\title{
Dependence of physical and mechanical properties of copper coatings on composition of chemical copper plating solution
}

\author{
(C) Ludmila A. Brusnitsina,${ }^{*+}$ Elena I. Stepanovskih, and Tatiana A. Alekseeva \\ Physical Chemistry and Chemistry of Colloids Academic Department. \\ Ural Federal University Named after the First President of Russia B.N. Yeltsin. \\ Mira St., 19. Yekaterinburg, 620002. Russia.E-mail: brusnitsyna.l@yandex.ru
}

\begin{abstract}
*Supervising author; ${ }^{+}$Corresponding author Keywords: chemical copper plating, speed copper plating, reaction order on components, energy of activation, plasticity of a copper covering.
\end{abstract}

\begin{abstract}
Chemical production of metal coatings is relevant and widely sought after. The field of practical use of chemical metal deposition reactions from aqueous solutions are continuously expanding. These reactions are widely used to obtain metal coatings for various purposes and begin to be used for the selective deposition of metals on a substrate in the form of patterns. Chemical copper plating has gained great practical importance. In additive and subtractive technology for the production of printed circuit boards, thick-layer chemical copper plating solutions are used to obtain a circuit diagram and metallization of holes. These are solutions that avoid the stage of galvanic copper plating, since the chemically deposited copper layer is sufficiently thick and allows further technological operations to be carried out.

Chemical copper plating solutions must be stable, work with a sufficient copper plating rate and, most importantly, the resulting copper coatings have high physical and mechanical properties. This is due to the fact that during operation, printed circuit boards can be significantly heated, which leads to thermal expansion of both the board material and the copper coating. Due to the difference in the linear expansion coefficients of the substrate material and the deposited copper, significant stresses can occur in the copper layer deposited on the walls of the holes of the printed circuit board. When applying an inelastic copper coating, the layer breaks and the board exits the operating mode.

This work is devoted to the study of the effect of some inorganic oxidizing agents on the properties of chemically precipitated copper, and this effect mainly affects the reduction of oxygen fragility.

The mechanism of the process of chemical copper plating of a dielectric surface activated by palladium(II) salts is considered in detail. It is shown that at a high deposition rate of chemical copper, hydrogen is included in the coating, which leads to the appearance of "hydrogen" brittleness. Bubbling a solution of chemical copper plating with air increases the stability of the solution and can be used to oxidize certain forms of organic additives introduced into the solution to reduce hydrogen embrittlement.

It is established that the incorporation of particles of copper oxide or hydroxide of monovalent copper into the copper coating leads to a decrease in the ductility of the copper coating and a decrease in the relative elongation of the chemically deposited copper layers. It was shown that in order to reduce the "oxygen" brittleness or increase the ductility of copper coatings, inorganic oxidants - ammonium persulfate and ferric sulfate salts must be introduced into the solution of chemical copper plating. Based on the experiments, it was found that in order to improve the ductility of the resulting copper coatings, ferric sulfate $\left(\mathrm{Fe}_{2}\left(\mathrm{SO}_{4}\right)_{3} \cdot 9 \mathrm{H}_{2} \mathrm{O}\right)$ in the amount of $0.15-0.2 \mathrm{~g} \cdot \mathrm{l}^{-1}$.

The conducted research cycle allowed us to recommend the following composition of a solution of thick-layer chemical copper plating, $\mathrm{mol} \cdot \mathrm{l}^{-1}$ : $\mathrm{CuSO}_{4}-0.1 ; \mathrm{KNaTart}-0.21 ; \mathrm{NaOH}-0.375 ; \mathrm{Na}_{2} \mathrm{CO}_{3}-0.028$; $\mathrm{K}_{3} \mathrm{Fe}(\mathrm{CN})_{6}-3 \cdot 10^{-5} ; \mathrm{Fe}_{2}\left(\mathrm{SO}_{4}\right)_{3}-3 \cdot 10^{-4} ; \mathrm{NiCl}_{2}-1.3 \cdot 10^{-2}$; ПАВ-2K $-0.1 \mathrm{~g} / \mathrm{l}$; formaldehyde $-25 \mathrm{ml} \cdot 1^{-1} 40 \%$ solution. The solution is stable during operation, the coating deposition rate is from 3 to $4 \mu \mathrm{m} \cdot \mathrm{h}^{-1}$, the plasticity of the resulting copper layers is $4-5 \%$.
\end{abstract}

\section{References}

[1] A.M. Medvedev. Technologies of printed circuit boards production. Moscow: Technosphere. 2005. 360p. (russian) 
[2] L.A. Brusnitsina, E.I. Stepanovskih, and T.A. Alekseeva. Restoration of the catalytic activity of the surface and stabilization of the activating solution based on copper(I) before chemical copper plating. Butlerov Communications. 2019. Vol.59. No.8. P.92-97. DOI: 10.37952/ROI-jbc-01/19-59-8-92

[3] L.A. Brusnitsyna, T.A. Alekseeva, E.I. Stepanovskikh. Dynamics of palladium (II) and tin (II) concentration changes in the activating solution. Journal of Applied Chemistry. 2016. Vol.89. No.9. P.1121-1128. (russian)

[4] M. Kapitsa. Chemical metallization of a dielectric. Electronic industry technology. 2005. No.6. P.35-39. (russian)

[5] M. Salkauskas, A. Vaskelis. Chemical metallization of plastics. Leningrad: Chemistry. 1985. 144p. (russian)

[6] V.V. Sviridov. Chemical precipitation of metals from aqueous solutions. Minsk: University. 1987. 270p. (russian)

[7] A.M. Kuznetsov. The catalytic effect of a conducting surface on a reaction of homogeneous external sphere electron transfer. Electrochemistry. 1991. Vol.27. No.11. P.1516-1521. (russian)

[8] E.I. Stepanovskikh, G.A. Zemko. Investigation of the properties of copper coatings from trilonate solutions of chemical copper plating. Journal of Applied Chemistry. 1989. No.6. P.1230-1233. (russian) 